\title{
Seroprevalence of Mycoplasma pneumoniae Specific IgM and IgG Antibodies in Asymptomatic Preschool Aged Children of Tehran, Iran,
}

\section{0}

\author{
Anahita Sanaei Dashti, ${ }^{1}$ Seyede Masumeh Hashemi, ${ }^{2}$ Mehrdad Halaji, ${ }^{3}$ Reza Arjmand, ${ }^{4,}$ and Fariba \\ Shirvani ${ }^{5}$ \\ ${ }^{1}$ Shiraz HIV/AIDS Research Center, Institute of Health, Shiraz University of Medical Sciences ,Shiraz, Iran \\ ${ }^{2}$ Pediatric Infectious Diseases Research Center, Shahid Beheshti University of Medical Sciences, Tehran, Iran \\ ${ }^{3}$ Professor Alborzi Clinical Microbiology Research Center, Namazi Hospital, Shiraz University of Medical Sciences, Shiraz, Iran \\ ${ }^{4}$ Department of Pediatric, Emam Ali Hospital, Alborz University of Medical Sciences, Karaj, Iran \\ ${ }^{5}$ Subspecialist in Pediatric Infectious Diseases, Associate Professor, Pediatric Infectious Diseases Research Center (PIRC) Mofid Children's Hospital, Shahid Beheshti University \\ of Medical Sciences, Tehran, Iran \\ "Corresponding author: Reza Arjmand, Department of Pediatric, Emam Ali Hospital, Alborz University of Medical Sciences, Karaj, Iran. Fax: +98-2632546372, E-mail: \\ r.arjmand30@yahoo.com
}

Received 2016 July 16; Revised 2016 December 12; Accepted 2017 January 07.

\begin{abstract}
Background: Respiratory tract diseases in children are one of the two leading causes of death worldwide and Mycoplasma pneumonia is the most important etiologic agent of respiratory tract infections.

objectives: This study aimed at determining the seroprevalence of Mycoplasma pneumoniae specific IgM and IgG antibodies in asymptomatic 5- to 6-year-old children in Tehran, Iran.

Methods: This cross sectional study was conducted during summer season of year 2010 in Tehran, North of Iran. Overall, 291 children were enrolled in the study in a sequential method. Blood samples were obtained from each child and the serum was separated and stored frozen at $-70^{\circ} \mathrm{C}$ for later antibody assay. Detection of IgM and IgG antibodies against M. pneumoniae was performed using commercial qualitative Enzyme Linked Immunosorbent Assay (ELISA) kits.

Results: Of the 291 participants in the present study, 156 (53.6\%) were female and 135 (46.4\%) were male. Overall, 73 (25.1\%) serum samples had positive results for M. pneumoniae specific IgG. The frequency of positivity and mean of titers for M. pneumoniae specific IgG antibody among males and females was 31(23\%), $17.4 \pm 5.5 \mathrm{U} / \mathrm{mL}$ (95\% CI 16.77-18.03) (ranged from 12.2 to $33 \mathrm{U} / \mathrm{mL}$ ), and 42 (26.9\%); $17.1 \pm 4.4 \mathrm{U} / \mathrm{mL}$ (95\% CI 16.6 - 17.6) (ranged from 12 to $28 \mathrm{U} / \mathrm{mL}$ ), respectively. Moreover, all tested serum samples for M. pneumoniaespecific IgM were negative.

Conclusions: In summary, our findings present the frequency of recent and previous exposure to M. pneumoniae infection among asymptomatic children aged from 5 to 6 years old in our region. Moreover, findings of such surveillance studies could provide useful insight to compare our situation with others.
\end{abstract}

Keywords: Seroepidemiological Studies, ELISA, Children, Iran, Mycoplasma pneumoniae

\section{Background}

Mycoplasma pneumoniae is one of the most important etiological agents of respiratory tract infections (1). Respiratory tract diseases in children are one of the leading causes of death worldwide (2).

Mycoplasma pneumoniae and Chlamydophila pneumoniae are causes of $5 \%$ to $10 \%$ of cases of upper respiratory tract infections including, tracheobronchitis, pharyngitis, laryngitis, and sinusitis (3). It was shown that in community-acquired pneumonia (CAP) cases, M. pneumoniae was isolated from up to $40 \%$ of samples, and more than $18 \%$ of samples from hospitalized children (1). Mycoplasma pneumoniae infections appear in an epidemic pattern every few years (every 3 to 7 years), yet may also remain totally asymptomatic (4-6). Moreover, M. pneumoniae infection can occur before the onset of asthma, which is accompanied by worsened symptoms, and even deteriorates the management of asthma (7).

It has widely been accepted that M. pneumoniae may be rather uncommon in children aged less than 5 years, and most common in 5- to 15-year-old children with a decreasing rate in adulthood (8). However, newer information showed more broad age spectrum, especially in less than 5year-old children (9). Also, the prevalence of M. pneumoniae infection in children less than 4 years old was documented by the report of 2010 to 2011 European epidemic data (10). In a research in Rasht, $M$. pneumoniae prevalence was $1 \%$ in 
261 children with acute respiratory infections (11). In another study from Shiraz, 10\% of children with acute lower respiratory infection had positive polymerase chain reaction (PCR) results for M. pneumoniae (12). Due to the fastidious nature of M. pneumoniae, culturing, and PCR methods are time consuming and expensive; therefore, diagnosis of the organism is usually done by serological tests (13).

Primary infection with M.pneumoniae indicated by IgM antibody increases during the first weeks, which can persist for a few months from the beginning of infection (14). About two weeks after primary infection, IgG antibody appears $(8,14)$. Detection of M.pneumoniae specific IgM could be a marker of recent infection, particularly in children (15). As a probable result of repeated exposures to M. pneumoniae, adults may not produce a measurable IgM antibody. Thus, it seems that determining the IgM and IgG antibodies in pediatric population, is a valuable epidemiological tool to assess the burden of recent or previous exposures to the bacteria.

\section{Objectives}

This study was conducted to determine the seroprevalence of Mycoplasma pneumoniae specific IgM and IgG antibodies in asymptomatic 5- to 6-year-old children in Tehran, Iran.

\section{Methods}

\subsection{Subjects and Study Design}

This cross sectional study was conducted within the summer season of year 2010 in Tehran, North of Iran. In total, 291 children were enrolled in the study in a sequential method. Tehran city was divided to five regions based on its 22 districts: northern, eastern, central, western, and southern districts. One health care center was chosen from each region and the sample size in each region was approximately equal. The inclusion criteria were age of 5 to 6 years old, and having been referred to health care centers as part of their vaccination program. All children were healthy and had no symptoms. Children were excluded from this study if they had any chronic disease, especially autoimmune diseases, history of blood transfusions or immunosuppressive therapy. This study was in accordance with the declaration of Helsinki and was approved by the ethics committee of Shahid Beheshti University of Medical Sciences. An Informed consent was obtained from children's parents before the study initiation.

\subsection{Sampling and Antibodies Detection}

Blood samples were obtained from each child and the serum was separated and stored frozen at $-70^{\circ} \mathrm{C}$ for later antibody assay. Detection of IgM and IgG antibodies against M. pneumoniae was performed on specimens using commercial qualitative Enzyme Linked Immunosorbent Assay (ELISA) kits (IBL-GmbH, Hamburg, Germany), according to the manufacturer's instructions. A titer of IgM and IgG antibodies greater than $12 \mathrm{U} / \mathrm{mL}$ was considered as positive, a value less than $8 \mathrm{U} / \mathrm{mL}$ as a negative result, and the borderline titers ( 8 to $12 \mathrm{U} / \mathrm{mL}$ ) accounted as negative.

\subsection{Statistical Analysis}

The results were presented as descriptive statistics in terms of relative frequency. Statistical analysis was performed using the SPSS ${ }^{\mathrm{TM}}$ software, version 21.0 (IBM Corp., USA). Chi-square was used to analyze the results and $\mathrm{P}<$ 0.05 was considered as statistically significant.

\section{Results}

Of the 291 children in the present study, 156 (53.6\%) were female and 135 (46.4\%) were male. Overall, 73 (25.1\%) of the serum samples were positive for M. pneumoniae specific IgG. Furthermore, 156 (53.6\%) and 62 (21.3\%) of the samples were negative and equivocal for M. pneumoniaespecific IgG, respectively. The mean \pm SD M. pneumoniae specific IgG positivity was $17.2 \pm 4.9 \mathrm{U} / \mathrm{mL}$, with a range from 12.1 to $33 \mathrm{U} / \mathrm{mL}$. The frequency of positivity and mean of titers for M. pneumoniae specific IgG antibody among males and females was 31(23\%), $17.4 \pm 5.5 \mathrm{U} / \mathrm{mL}$ (95\% CI 16.77 - 18.03) (range from 12.2 to $33 \mathrm{U} / \mathrm{mL}$ ) and 42 (26.9\%); and 17.1 $\pm 4.4 \mathrm{U} / \mathrm{mL}$ (95\% CI 16.6 - 17.6) (range from 12 to $28 \mathrm{U} / \mathrm{mL}$ ), respectively. There was no significant difference between the positivity and mean IgG titers. The distribution pattern of M. pneumoniae specific IgG titers for studied children is demonstrated in Figure 1.

All tested serum samples for $M$. pneumoniae specific IgM had negative results. The overall mean of IgM titers was $3.4 \pm 1 \mathrm{U} / \mathrm{mL}$ (ranged from 2 to $6 \mathrm{U} / \mathrm{mL}$ ). In terms of specific IgM mean titers, no significant difference was observed between male and female children $(P \geq 0.05)$.

\section{Discussion}

This study confirm that in preschool children no case with positive IgM anti-M. pneumoniae results was detected, which can be concluded that the majority of children had not been exposed to M. pneumoniae over 6 months to 1 year prior to sampling. 


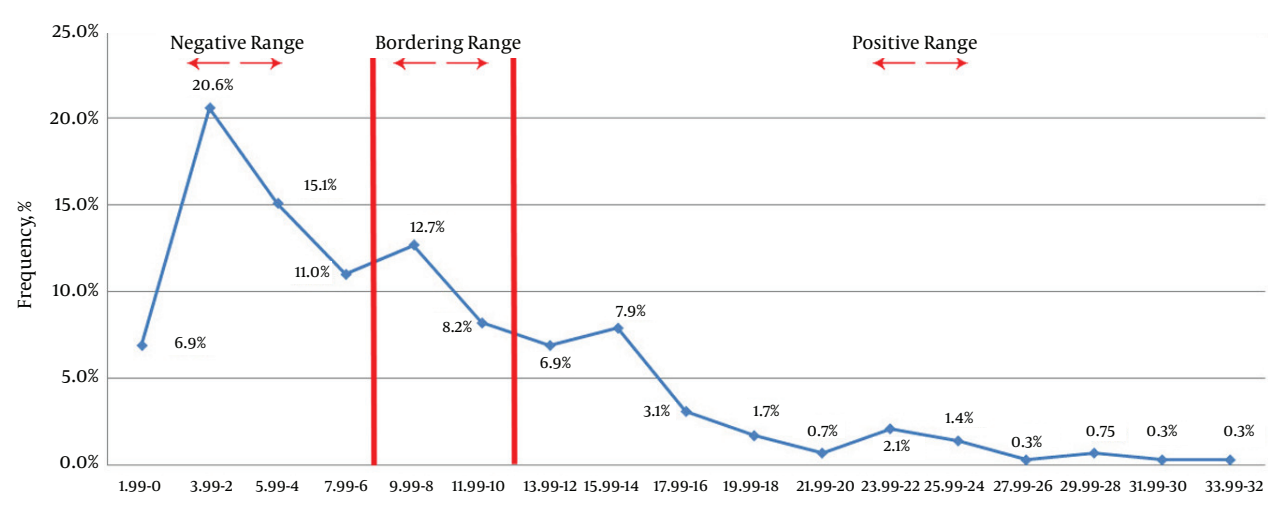

IgG antibody Titers, $\mathrm{U} / \mathrm{mL}$

Figure 1. The Distribution Pattern of Mycoplasma pneumoniae Specific IgG Titers in Children Aged from 5 to 6 Years, Within Tehran During Year 2010

Using a single serum specimen for detection of acute infection with M. pneumoniae had a sensitivity of $31.8 \%$ in Japanese children with pneumonia. The number increased to $88.6 \%$ when paired acute and convalescent sera were utilized (16). Our study sampling was carried out during the summer season. The temperature could have various effects on the frequency of some respiratory tract pathogens (17). Mycoplasma pneumoniae IgM in winter was found significantly higher compared to other seasons (18).

In a study on patients with respiratory tract infection in Tabriz, presence of M. pneumoniae infection was detected by culture, ELISA, and PCR methods, and the prevalence of M. pneumoniae with these tests was 6.15\%, 5.3\%, and $2.01 \%$, respectively. Overall, $53 \%$ of patients had elevated IgG level and only 5.3\% had IgM positive test results, which indicated active M. pneumoniae infection (19). In a study in Greek, 225 children, who were hospitalized for respiratory tract infections were assessed regarding the presence of IgG and IgM antibodies by ELISA (20). Mycoplasma pneumoniae infection was diagnosed in 25 (11.1\%) cases, as the second most common detected microorganism. In individuals with respiratory tract symptoms, the proportion of M. pneumoniae infection was significantly higher in the age group of 8 to 14 years than 0 to 3 years old group (20). In a prospective study with 93 admitted children in India, IgM antibody against $M$. pneumoniae was detected in $23.96 \%$ of symptomatic children by ELISA (21). The highest rate of infection was found in the 2 to 5 and 5- to 10-year-old groups (21). Another explanation for the negative rate of IgM antibody against $M$. pneumoniae in our study could be the type of selected children, who were asymptomatic while in the majority of the mentioned studies the enrolled population was those with respiratory tract infection symptoms.

One important factor in the seroprevalence pattern of M. pneumoniae could be the age of the tested individu- als. Several reports indicated that M. pneumoniae infection mostly affects school-aged children and young adults and patients above 5 years old than under 5 years old $(22,23)$. In another study, in a non-epidemic season, done by serology on healthy Finnish population, seroprevalence of M. pneumoniae was shown to increase in 2- to 4-year-old children and seroprevalence to M. pneumoniae increased in adolescence, yet, the increase leveled off at about $40 \%$ to $50 \%$ in adulthood (24). A study that investigated over 500 hospitalized children (the mean age was 4.49 years, ranging from 2 weeks to 14 years) with lower respiratory tract infections for M. pneumoniae using molecular and serological methods in Tunis, found that $61.5 \%$ of diagnosed cases, were under 5 years old (25).

IgG against $M$. pneumoniae typically tracks the IgM response 2 weeks later and can remain positive after many years of infection (8). A M. pneumoniae infection was confirmed through high IgG antibody titers (26). Our results showed that $25 \%$ of preschool aged children had M. pneumoniae IgG that means they had at least one episode of infection with the organism in their lifetime.

In our study, gender did not have any significant association with rate of M. pneumoniae IgG positivity. Similar to our findings, Touati et al. stated that despite the greater number of girls with positive anti-M. pneumoniae IgG than boys in Tunisian patients with an acute M. pneumoniae infection, there was no significant relationship between gender and IgG positivity (25). Finally, our study had some limitations. First, using single serum specimen in the present study to detect M. pneumoniae IgM may miss some true recent infections.. Second, our studied subjects were asymptomatic children, expected to have lower rate of recent infection with M. pneumoniae.

In summary, beside the limitations, our findings showed frequency of recent and previous exposure to $M$. 
pneumoniae infection among asymptomatic children aged from 5 to 6 years old in our region. Moreover, findings of such surveillance studies could provide useful insights to compare our situation with others.

\section{Acknowledgments}

We would like to thank the Pediatric Infections Research Center affiliated to Shahid Beheshti University of Medical Sciences, Tehran, Iran, for their financial support of this research. This article was based on Dr Seyede Masumeh Hashemi's thesis.

\section{Footnotes}

Authors' Contribution: Study concept and design, Anahita Sanaei Dashti; acquisition of data, Seyede Masumeh Hashemi and Reza Arjmand; analysis and interpretation of data, Seyede Masumeh Hashemi; drafting of the manuscript, Anahita Sanaei Dashti and Mehrdad Halaji; critical revision of the manuscript for important intellectual content, Anahita Sanaei Dashti; study supervision, Anahita Sanaei Dashti.

Financial Disclosure: We had no financial interests related to the material in the manuscript.

Conflict of Interests: There were no conflicts of interest. Funding/Support: This study was financially supported by Shahid Beheshti University of Medical Sciences, Tehran, Iran.

\section{References}

1. Kashyap S, Sarkar M. Mycoplasma pneumonia: Clinical features and management. Lung India. 2010;27(2):75-85. doi: 10.4103/09702113.63611. [PubMed: 20616940].

2. Selvaraj K, Chinnakali P, Majumdar A, Krishnan IS. Acute respiratory infections among under-5 children in India: A situational analysis. J Nat Sci Biol Med. 2014;5(1):15-20. doi: 10.4103/0976-9668.127275. [PubMed: 24678190].

3. She RC, Thurber A, Hymas WC, Stevenson J, Langer J, Litwin CM, et al. Limited utility of culture for Mycoplasma pneumoniae and Chlamydophila pneumoniae for diagnosis of respiratory tract infections. $J$ Clin Microbiol. 2010;48(9):3380-2. doi: 10.1128/JCM.00321-10. [PubMed: 20610673].

4. Lind K, Benzon MW, Jensen JS, Clyde WJ. A seroepidemiological study of Mycoplasma pneumoniae infections in Denmark over the 50-year period 1946-1995. Eur J Epidemiol. 1997;13(5):581-6. [PubMed: 9258572].

5. Layani-Milon MP, Gras I, Valette M, Luciani J, Stagnara J, Aymard M, et al. Incidence of upper respiratory tract Mycoplasma pneumoniae infections among outpatients in Rhone-Alpes, France, during five successive winter periods. J Clin Microbiol. 1999;37(6):1721-6. [PubMed: 10325314].

6. Hauksdottir GS, Jonsson T, Sigurdardottir V, Love A. Seroepidemiology of Mycoplasma pneumoniae infections in Iceland 1987-96. Scand J Infect Dis. 1998;30(2):177-80. doi: 10.1080/003655498750003591. [PubMed: 9730307].
7. Hong SJ. The Role of Mycoplasma pneumoniae Infection in Asthma. Allergy Asthma Immunol Res. 2012;4(2):59-61. doi: 10.4168/aair.2012.4.2.59. [PubMed: 22379599].

8. Waites KB, Talkington DF. Mycoplasma pneumoniae and its role as a human pathogen. Clin Microbiol Rev. 2004;17(4):697-728. doi: 10.1128/CMR.17.4.697-728.2004. [PubMed: 15489344] table of contents.

9. Vervloet LA, Marguet C, Camargos PA. Infection by Mycoplasma pneumoniae and its importance as an etiological agent in childhood community-acquired pneumonias. Braz J Infect Dis. 2007;11(5):507-14. doi:10.1590/S1413-86702007000500012. [PubMed: 17962878].

10. Gadsby NJ, Reynolds AJ, McMenamin J, Gunson RN, McDonagh S, Molyneaux PJ, et al. Increased reports of Mycoplasma pneumoniae from laboratories in Scotland in 2010 and 2011 - impact of the epidemic in infants. Euro Surveill. 2012;17(10) [PubMed: 22433597].

11. Naghipour M, Cuevas LE, Bakhshinejad T, Mansour-Ghanaei F, Noursalehi S, Alavy A, et al. Contribution of viruses, Chlamydia spp. and Mycoplasma pneumoniae to acute respiratory infections in Iranian children. J Trop Pediatr. 2007;53(3):179-84. doi: 10.1093/tropej/fmlo89. [PubMed: 17287243].

12. Hadi N, Kashef S, Moazzen M, Pour MS, Rezaei N. Survey of Mycoplasma pneumoniae in Iranian children with acute lower respiratory tract infections. Braz J Infect Dis. 2011;15(2):97-101. doi: 10.1590/S1413-86702011000200001. [PubMed: 21503393].

13. Zhang L, Zong ZY, Liu YB, Ye H, Lv XJ. PCR versus serology for diagnosing Mycoplasma pneumoniae infection: a systematic review \& metaanalysis. Indian J Med Res. 2011;134:270-80. [PubMed: 21985809].

14. Daxboeck F, Krause R, Wenisch C. Laboratory diagnosis of Mycoplasma pneumoniae infection. Clin Microbiol Infect. 2003;9(4):26373. [PubMed: 12667235].

15. Narita M. [Evaluation of ELISA kits for detection of Mycoplasma pneumoniae-specific IgG, IgA, IgM antibodies on the diagnosis of Mycoplasma pneumoniae infection in children]. Kansenshogaku Zasshi. 2005;79(7):457-63. [PubMed: 16119804]

16. Ozaki T, Nishimura N, Ahn J, Watanabe N, Muto T, Saito A, et al. Utility of a rapid diagnosis kit for Mycoplasma pneumoniae pneumonia in children, and the antimicrobial susceptibility of the isolates. J Infect Chemother. 2007;13(4):204-7. doi: 10.1007/s10156-007-0519-6. [PubMed: 17721681]

17. du Prel JB, Puppe W, Grondahl B, Knuf M, Weigl JA, Schaaff F, et al. Are meteorological parameters associated with acute respiratory tract infections? Clin Infect Dis. 2009;49(6):861-8. doi: 10.1086/605435. [PubMed: 19663691].

18. Sidal M, Kilic A, Unuvar E, Oguz F, Onel M, Agacfidan A, et al. Frequency of Chlamydia pneumoniae and Mycoplasma pneumoniae infections in children. J Trop Pediatr. 2007;53(4):225-31. doi: 10.1093/tropej/fmm003. [PubMed: 17517817].

19. Ghotaslou R, Sharifi S, Akhi MT, Soroush MH. Epidemiology, clinical features, and laboratory detection of Mycoplasma pneumoniae infection in East Azerbaijan, Iran. Turkish J Med Sci. 2013;43:521-4. doi: 10.3906/sag-1202-80.

20. Almasri M, Diza E, Papa A, Eboriadou M, Souliou E. Mycoplasma pneumoniae respiratory tract infections among Greek children. Hippokratia. 2011;15(2):147-52. [PubMed: 22110297].

21. Shenoy VD, Upadhyaya SA, Rao SP, Shobha KL. Mycoplasma pneumoniae infection in children with acute respiratory infection. $J$ Trop Pediatr. 2005;51(4):232-5. doi: 10.1093/tropej/fmio08. [PubMed: 15980029].

22. Chen Z, Ji W, Wang Y, Yan Y, Zhu H, Shao X, et al. Epidemiology and associations with climatic conditions of Mycoplasma pneumoniae and Chlamydophila pneumoniae infections among Chinese children hospitalized with acute respiratory infections. Ital J Pediatr. 2013;39:34. doi: 10.1186/1824-7288-39-34. [PubMed: 23705964].

23. Defilippi A, Silvestri M, Tacchella A, Giacchino R, Melioli G, Di Marco E, et al. Epidemiology and clinical features of Mycoplasma pneumoniae infection in children. Respir Med. 2008;102(12):1762-8. doi 10.1016/j.rmed.2008.06.022. [PubMed:18703327]. 
24. Tuuminen T, Varjo S, Ingman H, Weber T, Oksi J, Viljanen M. Prevalence of Chlamydia pneumoniae and Mycoplasma pneumoniae immunoglobulin $\mathrm{G}$ and A antibodies in a healthy Finnish population as analyzed by quantitative enzyme immunoassays. Clin Diagn Lab Immunol. 2000;7(5):734-8. [PubMed:10973446].

25. Touati A, Pereyre S, Bouziri A, Achour W, Khaldi A, Ben Jaballah N, et al. Prevalence of Mycoplasma pneumoniae-associated respiratory tract infections in hospitalized children: results of a 4-year prospective study in Tunis. Diagn Microbiol Infect Dis. 2010;68(2):103-9. doi: 10.1016/j.diagmicrobio.2010.05.010. [PubMed: 20846581].

26. Liu FC, Chen PY, Huang F, Tsai CR, Lee CY, Wang LC. Rapid diagnosis of Mycoplasma pneumoniae infection in children by polymerase chain reaction. J Microbiol Immunol Infect. 2007;40(6):507-12. [PubMed: 18087631]. 